\title{
Building superior lighting properties for WLEDs utilizing two-layered remote phosphor configurations
}

\author{
NGuYen DoAn Quoc AnH ${ }^{1}$, HoAng VAn NGOC ${ }^{2, *}$ \\ ${ }^{1}$ Power System Optimization Research Group, Faculty of Electrical and Electronics Engineering, Ton Duc Thang University, \\ Ho Chi Minh City, Vietnam \\ ${ }^{2}$ Institute of Applied Technology, Thu Dau Mot University, Binh Duong province, Vietnam
}

\begin{abstract}
The remote phosphor structure produces higher luminous flux but delivers poorer color quality than the conformal or in-cup phosphor structure. To eliminate this weakness, researchers have attempted to improve the chromatic properties of remote phosphor package. This study tends to enhance lighting features for WLEDs including color quality and luminous flux in general or color rendering index (CRI) and color quality scale (CQS) in particular by applying dual-layer remote phosphor structure. In the simulation section, we utilize two identical LEDs that only differ in correlated color temperature values which are $6600 \mathrm{~K}$ and $7700 \mathrm{~K}$. The study offers an idea of placing a yellow-green phosphor layer $\mathrm{SrBaSiO}_{4}: \mathrm{Eu}^{2+}$ or a red phosphor layer $\mathrm{Sr}_{\mathrm{w}} \mathrm{F}_{\mathrm{x}} \mathrm{B}_{\mathrm{y}} \mathrm{O}_{\mathrm{z}}: \mathrm{Eu}^{2+}, \mathrm{Sm}^{2+}$ on the yellow phosphor layer $\mathrm{YAG}: \mathrm{Ce}^{3+}$ and then modifying the concentrations of $\mathrm{Sr}_{\mathrm{w}} \mathrm{F}_{\mathrm{x}} \mathrm{B}_{\mathrm{y}} \mathrm{O}_{\mathrm{z}}: \mathrm{Eu}^{2+}, \mathrm{Sm}^{2+}$ and $\mathrm{SrBaSiO}_{4}: \mathrm{Eu}^{2+}$ to the suitable values to improve the color quality and lumen output of WLEDs. The results show that red phosphor layer $\mathrm{Sr}_{\mathrm{w}} \mathrm{F}_{\mathrm{x}} \mathrm{B}_{\mathrm{y}} \mathrm{O}_{z}: \mathrm{Eu}^{2+}, \mathrm{Sm}^{2+}$ has a significant influence on CRI and CQS improvement. Particularly, the increase of $\mathrm{Sr}_{\mathrm{w}} \mathrm{F}_{\mathrm{x}} \mathrm{B}_{\mathrm{y}} \mathrm{O}_{\mathrm{z}}: \mathrm{Eu}^{2+}, \mathrm{Sm}^{2+}$ concentration leads to increased CRI and CQS because the red light component increases in WLEDs. On the other hand, the green phosphor layer $\mathrm{SrBaSiO}_{4}$ : $\mathrm{Eu}^{2+}$ only brings benefit to the luminous flux. However, the WLEDs' luminous flux and color quality drop sharply, when $\mathrm{Sr}_{\mathrm{w}} \mathrm{F}_{\mathrm{x}} \mathrm{B}_{\mathrm{y}} \mathrm{O}_{z}: \mathrm{Eu}^{2+}, \mathrm{Sm}^{2+}$ and $\mathrm{SrBaSiO}_{4}: \mathrm{Eu}^{2+}$ concentrations rise extremely, which is verified based on the Mie-scattering theory and the Lambert-Beer law. In short, the article provides general knowledge and primary information for the production of higher-quality WLEDs.
\end{abstract}

Keywords: WLEDs; $\mathrm{SrBaSiO}_{4}: \mathrm{Eu}^{2+} ; \mathrm{Sr}_{w} \mathrm{~F}_{x} \mathrm{~B}_{y} \mathrm{O}_{z}: \mathrm{Eu}^{2+}, \mathrm{Sm}^{2+}$; luminous efficacy; color uniformity; Mie-scattering theory

\section{Introduction}

Nowadays, the lighting industry favors phosphor-converted white light-emitting diodes (WLEDs) as one of the vital light sources because the WLEDs have outstanding features such as compactness, energy saving, low cost, and high chromatic stability [1]. Therefore, the application areas of WLEDs have spread over many different aspects in our life, for instance: landscape lighting, street lighting, backlighting, etc. However, until now, the influential challenges in WLEDs, involving the efficiency of light extraction and angular correlated color temperature (CCT) chromatic uniformity, have prevented WLEDs from establishing their dominance in the lighting market [2]. Additionally, the consecutive rise in demands of the market and applications requires emphasis on

*E-mail: ngochv@tdmu.edu.vn improving luminous efficiency and color quality [3]. One of the most typical techniques used to create white light is blending the blue light conversed from red phosphor with yellow light from the LED chip. Blending colors plays a vital role in lighting technology because the arrangement of phosphor layers can have enormous effect on the lumen performance, especially the color rendering index (CRI) [4-8]. Some familiar techniques to solve the problem, such as using dispensing coating phosphor structure or conformal coating phosphor structure have been proposed $[9,10]$. However, these structures do not provide high color quality because the light conversion of phosphor material sharply decreases, which is caused by the direct contact between the yellow emitting phosphor and the LED chip. As a result, the temperature at this contact increases, leading to the damage to the phosphor and the degradation 
of the WLEDs quality. Therefore, in order to avoid the outcome of the generated heat, many previous studies have proposed a remote phosphor packaging design, constructed by separating the phosphor from the LED chip, as an ideal method for improving quality of WLEDs. The backscattering and light transmission inside WLEDs can be reduced greatly when there is an adequate distance between phosphor and the LED chip, which helps to control the heat generated and then, not only the lumen output but also the color quality of WLEDs can be improved [11-16]. Such remote phosphor structure, however, is appropriate only at regular lighting since it does not fulfil all the requirements of other illumination applications. Hence, some innovative remote phosphor structures, which can diminish the phenomenon of phosphor backscattering towards the LED chip and thus enhance the luminous flux, are recommended for further advanced lighting. Another research revealed that using of an inverted cone lens encapsulant and a ring surrounding remote phosphor layer can redirect the light rays emitted from the LED chip to the LED surface. Moreover, this method considerably reduces the energy loss resulting from the internal reflection of the light rays in LED [17]. Using a patterned remote phosphor package with an empty zone in the perimeter area that is not coated with phosphor on the surface surroundings can yield higher angular CCT homogeneity and color stability [18]. Furthermore, the substrate with patterned sapphire in the remote phosphor structure can produce greater enhancement in the homogeneity of angular-dependent CCT in a far field pattern than in a normal pattern [19]. As a result, the remote phosphor structure consisting of two phosphor films has been introduced for a better light yield of WLEDs. Aforementioned studies emphasize the improvement of the chromatic uniformity as well as the luminous flux for WLEDs by applying the remote phosphor structure but they only focus on single-chip WLEDs with low correlated color temperatures (CCTs) because improving the lighting performance of WLEDs with higher CCTs is a challenging issue [20, 21]. In fact, no study comparing the utility of different double-layer phosphor configurations has been conducted, which impedes the WLEDs development in terms of enhancing their chromatic stability and uniformity as well as lumen output.

Two different double-layer remote phosphor structures to improve the color quality of WLEDs at different correlated color temperatures in the range of $6600 \mathrm{~K}$ to $7700 \mathrm{~K}$ have been proposed in this article. The first method is to employ the green phosphor layer $\mathrm{SrBaSiO}_{4}: \mathrm{Eu}^{2+}$ to generate more green-light portion in WLEDs and to increase the luminous flux as a result. The second idea is to use the red phosphor layer $\mathrm{Sr}_{\mathrm{w}} \mathrm{F}_{\mathrm{x}} \mathrm{B}_{\mathrm{y}} \mathrm{O}_{\mathrm{z}}: \mathrm{Eu}^{2+}, \mathrm{Sm}^{2+}$ to raise the red-light portion in WLEDs, resulting in enhanced color rendering index (CRI) and color quality scale (CQS). Additionally, this paper demonstrates the chemical compositions of $\mathrm{Sr}_{\mathrm{w}} \mathrm{F}_{\mathrm{x}} \mathrm{B}_{\mathrm{y}} \mathrm{O}_{\mathrm{z}}: \mathrm{Eu}^{2+}, \mathrm{Sm}^{2+}$ and $\mathrm{SrBaSiO}_{4}: \mathrm{Eu}^{2+}$ as well as their influence on the WLEDs optical performance. The research paper also figures out that both CRI and CQS show remarkable increase with the added red phosphor layer $\mathrm{Sr}_{\mathrm{w}} \mathrm{F}_{\mathrm{x}} \mathrm{B}_{\mathrm{y}} \mathrm{O}_{z}: \mathrm{Eu}^{2+}, \mathrm{Sm}^{2+}$. Meanwhile, the presence of the green $\mathrm{SrBaSiO}_{4}: \mathrm{Eu}^{2+}$ film enhances the lumen output significantly. However, to prevent the chromatic quality or luminescence from a steep decline when the concentration of green or red phosphor rises excessively, $\mathrm{SrBaSiO}_{4}: \mathrm{Eu}^{2+}$ and $\mathrm{Sr}_{\mathrm{w}} \mathrm{F}_{\mathrm{x}} \mathrm{B}_{\mathrm{y}} \mathrm{O}_{\mathrm{z}}: \mathrm{Eu}^{2+}, \mathrm{Sm}^{2+}$ concentrations should be adjusted properly. Besides, the addition of green or red phosphor layer in the WLED design results in two drawbacks: (1) the increase in green-light or red-light components extends the white-light spectra; (2) the WLEDs' internal scattering and light transmission are inversely proportional to the green or red phosphor concentration. Thus, the choice of suitable concentration for these two phosphor materials is crucial for maintaining a high luminous flux of WLEDs.

\section{Preparation}

\subsection{Preparation of $\mathrm{SrBaSiO}_{4}: \mathrm{Eu}^{2+}$ and $\mathbf{S r}_{\mathrm{w}} \mathbf{F}_{\mathrm{x}} \mathbf{B}_{\mathrm{y}} \mathbf{O}_{\mathrm{z}}: \mathbf{E u}^{2+}, \mathrm{Sm}^{2+}$ particles}

As yellow-green-emitting phosphor $\mathrm{SrBaSiO}_{4}: \mathrm{Eu}^{2+}$ and red-emitting phosphor $\mathrm{Sr}_{\mathrm{w}} \mathrm{F}_{\mathrm{x}} \mathrm{B}_{\mathrm{y}} \mathrm{O}_{z}: \mathrm{Eu}^{2+}, \mathrm{Sm}^{2+} \quad$ offer outstanding 
properties including high quantum efficiency and stability at high temperature, they have become popular rapidly, especially in high-loading and long lifespan fluorescent lamps [22]. Table 1 and Table 2 specifically depict the chemical composition of $\mathrm{SrBaSiO}_{4}: \mathrm{Eu}^{2+}$ and $\mathrm{Sr}_{\mathrm{w}} \mathrm{F}_{\mathrm{x}} \mathrm{B}_{\mathrm{y}} \mathrm{O}_{\mathrm{z}}: \mathrm{Eu}^{2+}, \mathrm{Sm}^{2+}$, respectively. Before being applied to WLEDs, these compositions need to be analyzed in detail to see how they affect the phosphor's optical properties. Accordingly, $\mathrm{SrBaSiO}_{4}: \mathrm{Eu}^{2+}$ emits yellow-green light at a peak wavelength of $2.36 \mathrm{eV}$. The existence of $\mathrm{Eu}^{2+}$ ions helps increase the illumination efficiency of $\mathrm{SrBaSiO}_{4}: \mathrm{Eu}^{2+}$. Meanwhile, $\mathrm{Sr}_{\mathrm{w}} \mathrm{F}_{\mathrm{x}} \mathrm{B}_{\mathrm{y}} \mathrm{O}_{\mathrm{z}}: \mathrm{Eu}^{2+}, \mathrm{Sm}^{2+}$ emits red light at many different peak wavelengths such as $684 \mathrm{~nm}, 693 \mathrm{~nm}, 697 \mathrm{~nm}, 703 \mathrm{~nm}, 723 \mathrm{~nm}$, $725 \mathrm{~nm}$, and $732 \mathrm{~nm}$. The attendance of the $\mathrm{Sm}^{2+}$ ion boosts the absorption at $395 \mathrm{~nm}, 420 \mathrm{~nm}$, and $502 \mathrm{~nm}$ of peak wavelengths. The appearance of multiple peaks is a proof of effectiveness of the red phosphor material $\mathrm{Sr}_{\mathrm{w}} \mathrm{F}_{\mathrm{x}} \mathrm{B}_{\mathrm{y}} \mathrm{O}_{\mathrm{z}}: \mathrm{Eu}^{2+}, \mathrm{Sm}^{2+}$, which yields higher optical efficiency.

To be applied to WLEDs, these phosphors must have a suitable blue-light spectrum. In other words, their sprectra must match those of the blue rays emitted from the LED chips. The absorption spectrum of $\mathrm{Sr}_{\mathrm{w}} \mathrm{F}_{\mathrm{x}} \mathrm{B}_{\mathrm{y}} \mathrm{O}_{\mathrm{z}}: \mathrm{Eu}^{2+}, \mathrm{Sm}^{2+}$ in the range of $250 \mathrm{~nm}$ to $502 \mathrm{~nm}$ is conducive to absorb the light emitted from various bands due to the fact that the light components in WLEDs consist of both blue rays from LED chips and the yellow rays converted from the yellow phosphor film. Similarly, $\mathrm{SrBaSiO}_{4}: \mathrm{Eu}^{2+}$ also has a wide absorption spectrum $(3.4 \mathrm{eV}$ to $4.88 \mathrm{eV})$ with more than $70 \%$ absorption efficiency.

The input parameters such as phosphor concentration, phosphor particle size, excitation spectrum, absorption spectrum, and phosphor emission spectrum should be accurately determined before performing the optical simulation of $\mathrm{SrBaSiO}_{4}: \mathrm{Eu}^{2+}$ and $\mathrm{Sr}_{\mathrm{w}} \mathrm{F}_{\mathrm{x}} \mathrm{B}_{\mathrm{y}} \mathrm{O}_{\mathrm{z}}$ : $\mathrm{Eu}^{2+}, \mathrm{Sm}^{2+}$ particles. Among the mentioned parameters, the phosphor concentration and the particle size are the most important figures to obtain the best color quality and luminescence efficiency of the WLED devices while the spectral parameters are constants. In this study, the phosphor particles have a fixed average diameter of
$14.5 \mu \mathrm{m}$. Thus, the final objective of this study is to modify the concentrations of $\mathrm{SrBaSiO}_{4}: \mathrm{Eu}^{2+}$ and $\mathrm{Sr}_{\mathrm{w}} \mathrm{F}_{\mathrm{x}} \mathrm{B}_{\mathrm{y}} \mathrm{O}_{\mathrm{z}}: \mathrm{Eu}^{2+}, \mathrm{Sm}^{2+}$ phosphors until they reach the optimal values.

\subsection{Constructing green-yellow two- layered phosphor and red-yellow two- layered phosphor configurations}

This study employs WLEDs with nine LED chips inside as shown in Fig. 1a. Each $1.16 \mathrm{~W}$ blue chip has an emitted wavelength peaking at $453 \mathrm{~nm}$. The detailed information on WLED configuration is given in Fig. 1b. Next, the remote phosphor models need to be constructed to determine the optimal concentration of $\mathrm{SrBaSiO}_{4}: \mathrm{Eu}^{2+}$ and $\mathrm{Sr}_{\mathrm{w}} \mathrm{F}_{\mathrm{x}} \mathrm{B}_{\mathrm{y}} \mathrm{O}_{\mathrm{z}}: \mathrm{Eu}^{2+}, \mathrm{Sm}^{2+}$. Accordingly, both green-yellow two-layered phosphor configuration (GYC) and red-yellow two-layered phosphor configuration (RYC) are presented in this study.

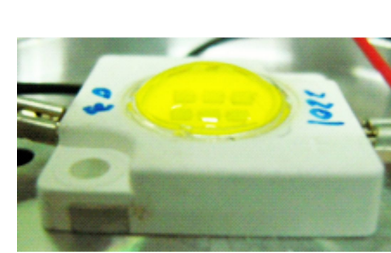

(a)

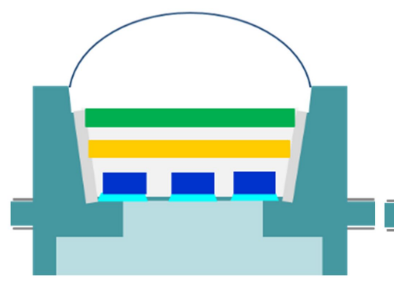

(c)
Lead frame: $4.7 \mathrm{~mm}$ Jentech Size-S

LED chip: $\mathrm{V} 45 \mathrm{H}$

Die attach: Sumitomo 1295SA

Gold Wire: $1.0 \mathrm{mil}$

Phosphor: ITC NYAG4_EL (b)

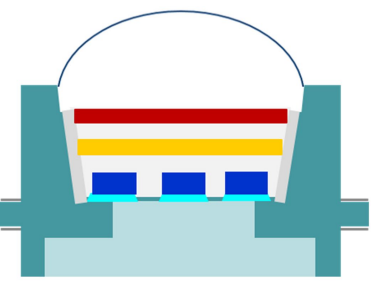

(d)
Fig. 1. Illustration of phosphor-converted MCWLEDs containing $\mathrm{SrBaSiO}_{4}: \mathrm{Eu}^{2+}$ : (a) the actual MCW-LEDs and (b) its parameters; (c) illustration of GYC, and (d) RYC.

Fig. 1c is the illustration of the GYC, in which a green phosphor layer $\mathrm{SrBaSiO}_{4}: \mathrm{Eu}^{2+}$ is above the yellow YAG: $\mathrm{Ce}^{3+}$ layer and both of them are located above the LED chips. Likewise, for the RYC, the structure is similar to the GYC but instead of the green phosphor film, there is the red phosphor $\mathrm{Sr}_{\mathrm{w}} \mathrm{F}_{\mathrm{x}} \mathrm{B}_{\mathrm{y}} \mathrm{O}_{\mathrm{z}}: \mathrm{Eu}^{2+}, \mathrm{Sm}^{2+}$ layer, 
Table 1. Composition of yellow-emitting $\mathrm{SrBaSiO}_{4}: \mathrm{Eu}^{2+}$ phosphor.

\begin{tabular}{lccccccc}
\hline Ingredient & $\begin{array}{c}\text { Mole } \\
{[\%]}\end{array}$ & $\begin{array}{c}\text { By weight } \\
{[\mathrm{g}]}\end{array}$ & $\begin{array}{c}\text { Molar mass } \\
{[\mathrm{g} / \mathrm{mol}]}\end{array}$ & $\begin{array}{c}\text { Mole } \\
{[\mathrm{mol}]}\end{array}$ & Ions & $\begin{array}{c}\text { Mole } \\
{[\mathrm{mol}]}\end{array}$ & $\begin{array}{c}\text { Mole } \\
{[\%]}\end{array}$ \\
\hline \hline $\mathrm{SrCO}_{3}$ & 31.28 & 145 & 147.63 & 0.982 & $\mathrm{Sr}^{2+}$ & 0.982 & 0.088 \\
$\mathrm{BaCO}_{3}$ & 31.79 & 197 & 197.34 & 0.998 & $\mathrm{Ba}^{2+}$ & 0.998 & 0.090 \\
$\mathrm{SiO}_{2}$ & 33.40 & 63 & 60.08 & 1.049 & $\mathrm{Si}^{4+}$ & 1.049 & 0.094 \\
$\mathrm{Eu}_{2} \mathrm{O}_{3}$ & 0.32 & 3.5 & 351.926 & 0.01 & $\mathrm{O}^{2-}$ & 8.068 & 0.726 \\
$\mathrm{NH}_{4} \mathrm{Cl}$ & 3.22 & 5.4 & 53.49 & 0.101 & $\mathrm{Eu}^{2+}$ & 0.02 & 0.002 \\
\hline
\end{tabular}

Table 2. Composition of red-emitting $\mathrm{Sr}_{\mathrm{w}} \mathrm{F}_{\mathrm{x}} \mathrm{B}_{\mathrm{y}} \mathrm{O}_{\mathrm{z}}: \mathrm{Eu}^{2+}, \mathrm{Sm}^{2+}$ phosphor.

\begin{tabular}{lccccccc}
\hline Ingredient & $\begin{array}{c}\text { Mole } \\
{[\%]}\end{array}$ & $\begin{array}{c}\text { By weight } \\
{[\mathrm{g}]}\end{array}$ & $\begin{array}{c}\text { Molar mass } \\
{[\mathrm{g} / \mathrm{mol}]}\end{array}$ & $\begin{array}{c}\text { Mole } \\
{[\mathrm{mol}]}\end{array}$ & Ions & $\begin{array}{c}\text { Mole } \\
{[\mathrm{mol}]}\end{array}$ & $\begin{array}{c}\text { Mole } \\
{[\%]}\end{array}$ \\
\hline \hline $\mathrm{Sr}\left(\mathrm{NO}_{3}\right)_{2}$ & 10.09 & 126.98 & 211.63 & 0.6 & $\mathrm{Sr}^{2+}$ & 0.6 & 0.0241 \\
$\mathrm{SrF}_{2}$ & 5.43 & 40.58 & 125.62 & 0.32 & $\mathrm{~F}^{-}$ & 0.646 & 0.0259 \\
$\mathrm{H}_{3} \mathrm{BO}_{3}$ & 84.12 & 309.2 & 61.83 & 5 & $\mathrm{~B}^{3+}$ & 5 & 0.203 \\
$\mathrm{Eu}_{2} \mathrm{O}_{3}$ & 0.25 & 5.28 & 351.93 & 0.015 & $\mathrm{O}^{2-}$ & 18.665 & 0.748 \\
$\mathrm{Sm}_{2} \mathrm{O}_{3}$ & 0.11 & 2.09 & 348.72 & 0.006 & $\mathrm{Eu}^{2+}$ & 0.03 & 0.0012 \\
& \multicolumn{2}{c}{$\mathrm{Sr}_{\mathrm{w}} \mathrm{F}_{\mathrm{x}} \mathrm{B}_{\mathrm{y}} \mathrm{O}_{\mathrm{z}}: \mathrm{Eu}^{2+}, \mathrm{Sm}^{2+}$} & & $\mathrm{Sm}^{2+}$ & 0.012 & 0.00048 \\
\hline
\end{tabular}

as described in Fig. 1d. The role of GYC and RYC here is to improve the color quality and luminescence of WLEDs. To achieve this objective, the green-light and red-light scattering and composition in WLEDs must be optimized. Nevertheless, both $\mathrm{SrBaSiO}_{4}: \mathrm{Eu}^{2+}$ and $\mathrm{Sr}_{\mathrm{w}} \mathrm{F}_{\mathrm{x}} \mathrm{B}_{\mathrm{y}} \mathrm{O}_{\mathrm{z}}: \mathrm{Eu}^{2+}, \mathrm{Sm}^{2+}$ concentrations need to be corrected appropriately.

According to Fig. 2, there are different changes in concentrations of the green $\mathrm{SrBaSiO}_{4}: \mathrm{Eu}^{2+}$, the yellow YAG:Ce ${ }^{3+}$, and the red $\mathrm{Sr}_{\mathrm{w}} \mathrm{F}_{\mathrm{x}} \mathrm{B}_{\mathrm{y}} \mathrm{O}_{\mathrm{z}}: \mathrm{Eu}^{2+}, \mathrm{Sm}^{2+}$, which means that the average CCTs are stabilized, and the scattering as well as the absorption properties of the two phosphor films are greatly affected, which inevitably influences the color quality and luminescence of WLEDs. Therefore, determining a suitable concentration of $\mathrm{SrBaSiO}_{4}: \mathrm{Eu}^{2+}$ and $\mathrm{Sr}_{\mathrm{w}} \mathrm{F}_{\mathrm{x}} \mathrm{B}_{\mathrm{y}} \mathrm{O}_{\mathrm{z}}: \mathrm{Eu}^{2+}, \mathrm{Sm}^{2+}$ will help to enhance WLEDs' color quality. When the concentration of $\mathrm{SrBaSiO}_{4}: \mathrm{Eu}^{2+}$ and $\mathrm{Sr}_{\mathrm{w}} \mathrm{F}_{\mathrm{x}} \mathrm{B}_{\mathrm{y}} \mathrm{O}_{\mathrm{z}}: \mathrm{Eu}^{2+}, \mathrm{Sm}^{2+}$ increases from $2 \mathrm{wt} . \%$ to $20 \mathrm{wt} . \%$ and from $2 \mathrm{wt} . \%$ to $26 \mathrm{wt} . \%$, respectively, the concentration of YAG: $\mathrm{Ce}^{3+}$ will decrease to maintain the average correlated color temperatures. This phenomenon
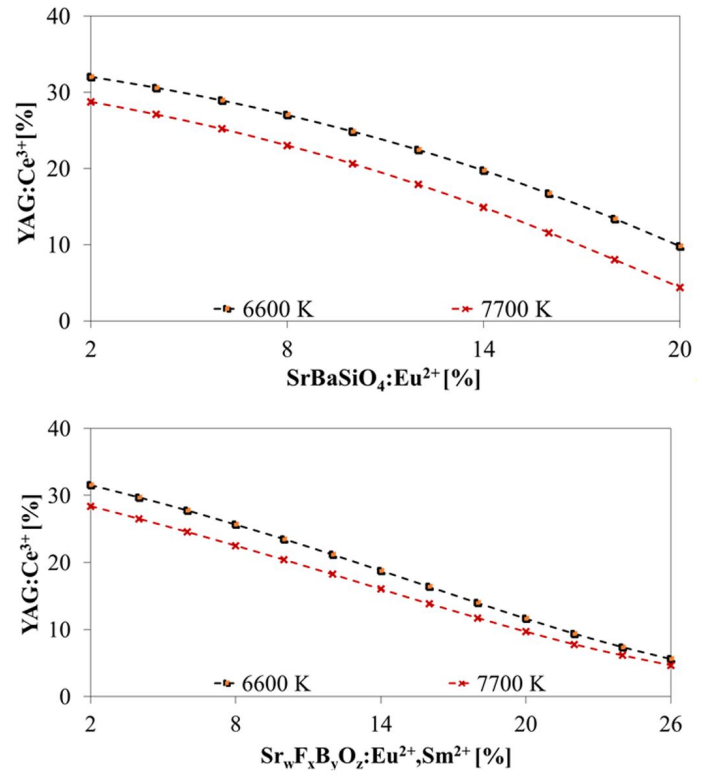

Fig. 2. Change in phosphor concentration of GYC (above) and RYC (below) necessary for keeping the average CCTs.

is the same for $6600 \mathrm{~K}$ and $7700 \mathrm{~K}$ WLEDs. The impact of the green phosphor $\mathrm{SrBaSiO}_{4}: \mathrm{Eu}^{2+}$ content on the WLED transmission spectrum, 
in Fig. 3, is the most obvious. The corrections of this concentration are made based on the manufacturers' requirements. It is possible to allow a small reduction in luminous flux when the WLEDs have higher color requirements. The light intensity within two spectrum bands, $420 \mathrm{~nm}$ to $480 \mathrm{~nm}$ and $500 \mathrm{~nm}$ to $640 \mathrm{~nm}$, tends to go up with $\mathrm{SrBaSiO}_{4}: \mathrm{Eu}^{2+}$ concentration, leading to the increase of luminous flux. In addition, the rise of scattered blue photons in WLED results in the rise of scattering events in the phosphor layers and WLEDs, and hence, the chromatic uniformity is well improved. This is why the $\mathrm{SrBaSiO}_{4}: \mathrm{Eu}^{2+}$ enhances WLEDs, especially in color homogeneity. On the other hand, the red phosphor $\mathrm{Sr}_{\mathrm{w}} \mathrm{F}_{\mathrm{x}} \mathrm{B}_{\mathrm{y}} \mathrm{O}_{\mathrm{z}}: \mathrm{Eu}^{2+}, \mathrm{Sm}^{2+}$ enhances WLEDs when color quality and luminous flux are concerned. Particularly, the red light spectrum tends to increase in the range from $648 \mathrm{~nm}$ to $738 \mathrm{~nm}$ with the $\mathrm{Sr}_{\mathrm{w}} \mathrm{F}_{\mathrm{x}} \mathrm{B}_{\mathrm{y}} \mathrm{O}_{\mathrm{z}}: \mathrm{Eu}^{2+}, \mathrm{Sm}^{2+}$ concentration. However, this spectrum development is not significant unless the spectrum of the two ranges $420 \mathrm{~nm}$ to $480 \mathrm{~nm}$ and $500 \mathrm{~nm}$ to $640 \mathrm{~nm}$ shows an increase to enhance the blue-light scattering. The emission spectra still get larger at the correlated color temperatures of $6600 \mathrm{~K}$ or even $7700 \mathrm{~K}$ if $\mathrm{Sr}_{\mathrm{w}} \mathrm{F}_{\mathrm{x}} \mathrm{B}_{\mathrm{y}} \mathrm{O}_{\mathrm{z}}: \mathrm{Eu}^{2+}, \mathrm{Sm}^{2+}$ is applied, although controlling the color quality of WLEDs at higher correlated color temperatures is very challenging. In conclusion, the red phosphor $\mathrm{Sr}_{\mathrm{w}} \mathrm{F}_{\mathrm{x}} \mathrm{B}_{\mathrm{y}} \mathrm{O}_{\mathrm{z}}: \mathrm{Eu}^{2+}, \mathrm{Sm}^{2+}$ has been proven to have the ability of improving color quality of WLEDs regardless of lower or higher correlated color temperatures.

\section{Computation and discussion}

CRI is known as the most useful quantitative approach used to measure the accuracy of color that a light source can expose when an object is illuminated. The green light portion exceeding the standard level cause the color imbalance to occur among primary colors of green, blue, and yellow; and this probably affects the chromatic performance of the WLED, resulting in its degraded color accuracy. Fig. 4 shows that CRI has a tendency to decrease with an additional phosphor layer of

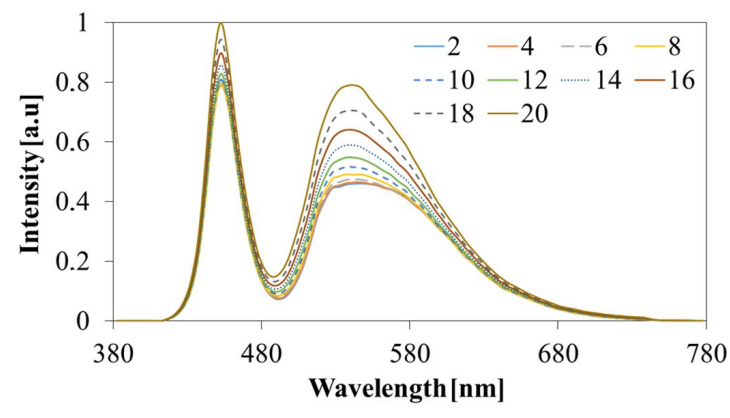

(a)

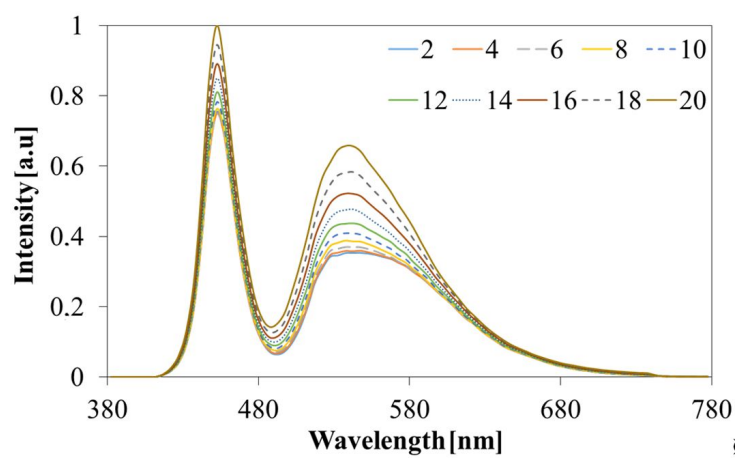

(b)

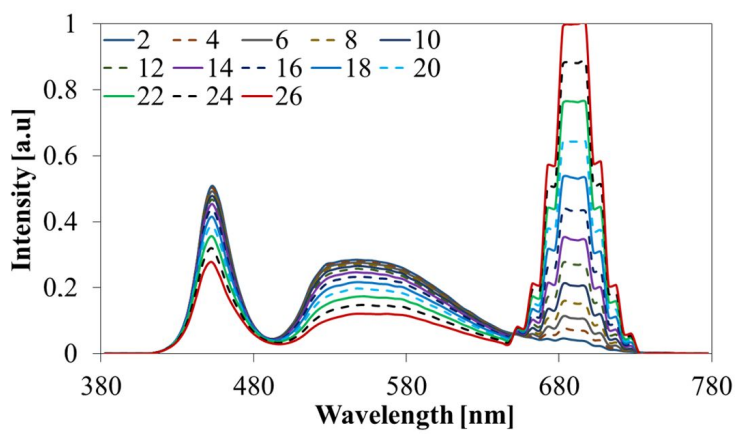

(c)

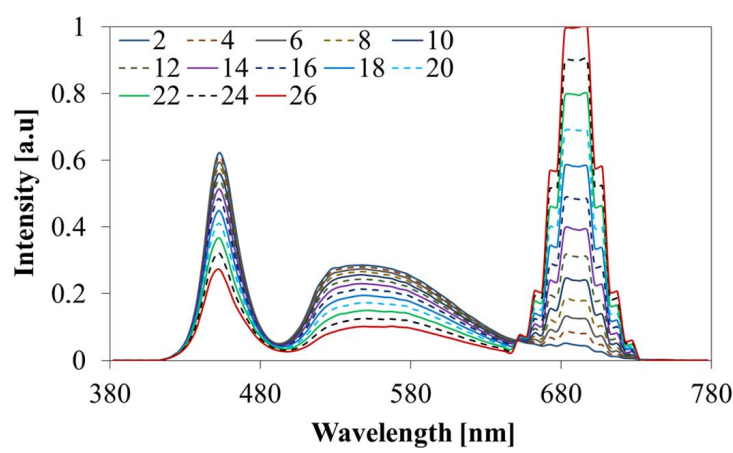

(d)

Fig. 3. Emission spectra of dual-layer phosphor configurations: (a) GYC (6600 K); (b) GYC (7700 K); (c) RYC (6600 K); (d) RYC (7700 K). 
$\mathrm{SrBaSiO}_{4}: \mathrm{Eu}^{2+}$ in the remote phosphor package. However, it is not quite reliable because CRI does not cover all the criteria of good WLEDs. CQS is another method for lighting quality determination and analysis, especially used as an alternative to unsaturated CRI colors, which is much more challenging to achieve than CRI. It can be seen from Fig. 5 that CQS does not change when the $\mathrm{SrBaSiO}_{4}: \mathrm{Eu}^{2+}$ concentration is less than $8 \%$. Therefore, $8 \%$ of $\mathrm{SrBaSiO}_{4}: \mathrm{Eu}^{2+}$ concentration is an optimal value to apply for WLEDs when taking emission of luminous flux into account. Fig. 4 also depicts a constant increase of color rendering index with the $\mathrm{Sr}_{\mathrm{w}} \mathrm{F}_{\mathrm{x}} \mathrm{B}_{\mathrm{y}} \mathrm{O}_{\mathrm{z}}$ : $\mathrm{Eu}^{2+}, \mathrm{Sm}^{2+}$ phosphor concentration, regardless of CCTs, which is the result of the red phosphor absorption. Exactly, as the LED chip emits blue rays, $\mathrm{Sr}_{\mathrm{w}} \mathrm{F}_{\mathrm{x}} \mathrm{B}_{\mathrm{y}} \mathrm{O}_{\mathrm{z}}: \mathrm{Eu}^{2+}, \mathrm{Sm}^{2+}$ particles absorb this blue light and convert it into the red one. Although $\mathrm{Sr}_{\mathrm{w}} \mathrm{F}_{\mathrm{x}} \mathrm{B}_{\mathrm{y}} \mathrm{O}_{z}: \mathrm{Eu}^{2+}, \mathrm{Sm}^{2+}$ phosphor also absorbs the yellow light apart from the blue one, the red light component in WLEDs still increases because the blue-light absorption is much stronger owing to the absorption nature of the red phosphor material. As a result, the color rendering index gets better with the addition of $\mathrm{Sr}_{\mathrm{w}} \mathrm{F}_{\mathrm{x}} \mathrm{B}_{\mathrm{y}} \mathrm{O}_{\mathrm{z}}: \mathrm{Eu}^{2+}, \mathrm{Sm}^{2+}$.

$\mathrm{CRI}$ is one of the most important factors in the selection of high-quality WLEDs among the parameters used to evaluate modern WLEDs, thereby the WLEDs with higher CRI usually cost much more. Nevertheless, $\mathrm{Sr}_{\mathrm{w}} \mathrm{F}_{\mathrm{x}} \mathrm{B}_{\mathrm{y}} \mathrm{O}_{\mathrm{z}}$ : $\mathrm{Eu}^{2+}{ }^{2} \mathrm{Sm}^{2+}$ phosphor can help to reduce this cost, bringing economic benefits to consumers. However, CRI is only an element of the color quality measurement of WLEDs. It is impossible to assure that a WLED provides an excellent chromatic quality just based on its high CRI. Hence, a new quantitative measurement named color quality scale (CQS) was introduced in our study. The CQS covers several aspects of color quality of objects illuminated by a light source involving color rendering, chromatic coordinates, and observer preferences. With such effective evaluation, CQS is almost a dominant index in determining WLEDs color quality. According to Fig. 5, the CQS rises considerably with increased $\mathrm{Sr}_{\mathrm{w}} \mathrm{F}_{\mathrm{x}} \mathrm{B}_{\mathrm{y}} \mathrm{O}_{\mathrm{z}}: \mathrm{Eu}^{2+}, \mathrm{Sm}^{2+}$ concentration. Therefore, using the $\mathrm{Sr}_{\mathrm{w}} \mathrm{F}_{\mathrm{x}} \mathrm{B}_{\mathrm{y}} \mathrm{O}_{\mathrm{z}}: \mathrm{Eu}^{2+}, \mathrm{Sm}^{2+}$
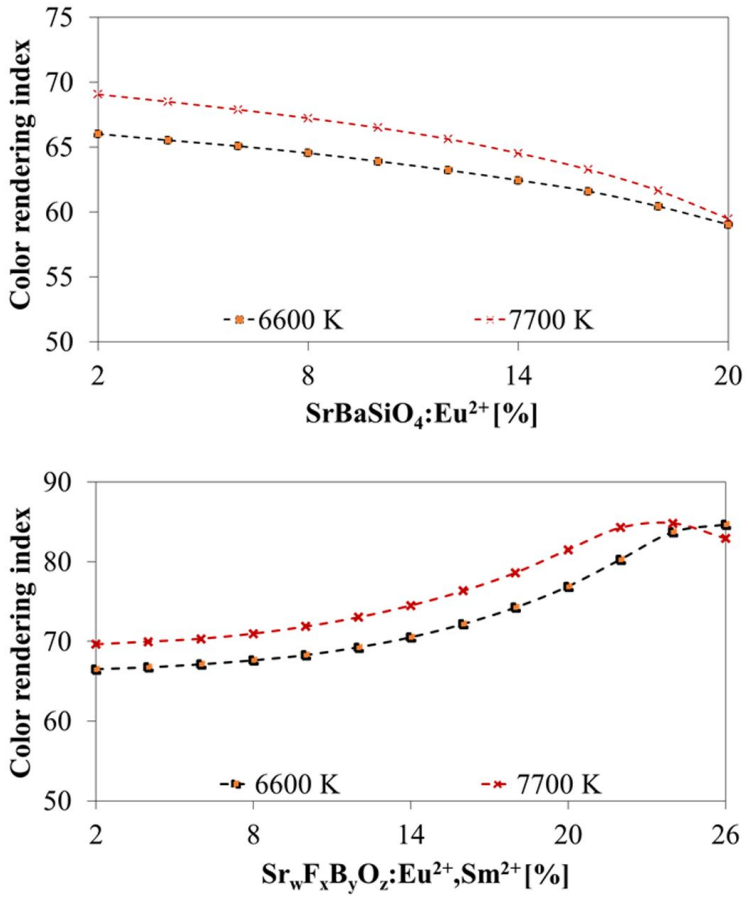

Fig. 4. Color rendering index as a function of $\mathrm{SrBaSiO}_{4}: \mathrm{Eu}^{2+}$ and $\mathrm{Sr}_{\mathrm{w}} \mathrm{F}_{\mathrm{x}} \mathrm{B}_{\mathrm{y}} \mathrm{O}_{\mathrm{z}}: \mathrm{Eu}^{2+}, \mathrm{Sm}^{2+}$ concentration: (above) GYC; (below) RYC.

phosphor with dual-layer phosphor structure can help to improve the color quality of WLEDs and reach the objectives of the study. However, the disadvantage of $\mathrm{Sr}_{\mathrm{w}} \mathrm{F}_{\mathrm{x}} \mathrm{B}_{\mathrm{y}} \mathrm{O}_{\mathrm{z}}: \mathrm{Eu}^{2+}, \mathrm{Sm}^{2+}$ in terms of luminous flux is worth our attention.

Next, in order to attain further advances in WLED optical performance, the transmitted blue light and converted yellow light in the two-layered phosphor structure have been carefully evaluated using the equations below.

In a single-layer remote phosphor structure whose phosphor layer is $2 \mathrm{~h}$ thick, the transmitted blue light and converted yellow light are calculated by:

$$
\begin{gathered}
P B_{1}=P B_{0} \times e^{-2 \alpha_{B 1} h} \\
P Y_{1}=\frac{1}{2} \frac{\beta_{1} \times P B_{0}}{\alpha_{B 1}-\alpha_{Y 1}}\left(e^{-2 \alpha_{Y 1} h}-e^{-2 \alpha_{B 1} h}\right)
\end{gathered}
$$

In a dual-layer phosphor packaging model, each phosphor film has a thickness of $h$, and computations of the transmitted blue light and converted 

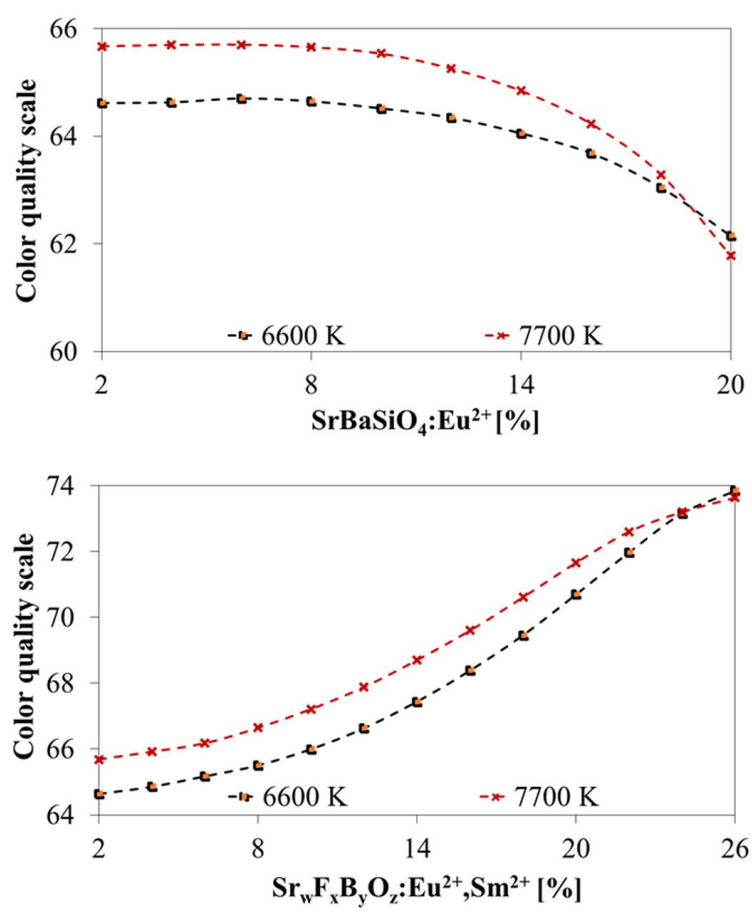

Fig. 5. The color quality scale as a function of $\mathrm{SrBaSiO}_{4}: \mathrm{Eu}^{2+}$ and $\mathrm{Sr}_{\mathrm{w}} \mathrm{F}_{\mathrm{x}} \mathrm{B}_{\mathrm{y}} \mathrm{O}_{\mathrm{z}}: \mathrm{Eu}^{2+}, \mathrm{Sm}^{2+}$ concentration: (above) GYC; (below) RYC.
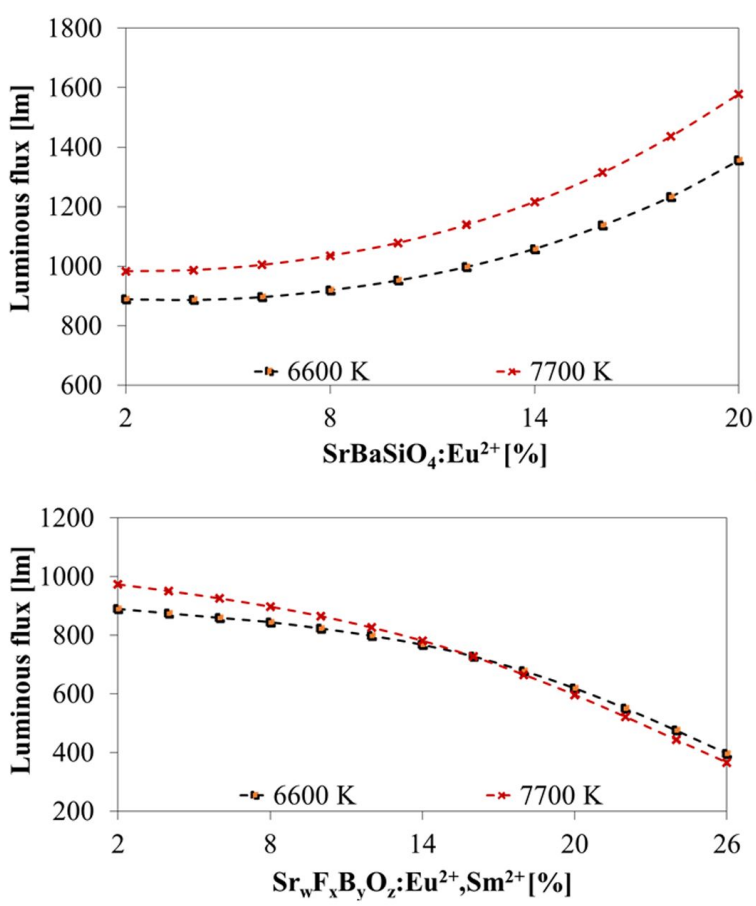

Fig. 6. Luminous flux as a function of $\mathrm{SrBaSiO}_{4}: \mathrm{Eu}^{2+}$ and $\mathrm{Sr}_{\mathrm{w}} \mathrm{F}_{\mathrm{x}} \mathrm{B}_{\mathrm{y}} \mathrm{O}_{\mathrm{z}}: \mathrm{Eu}^{2+}, \mathrm{Sm}^{2+}$ concentration: (above) GYC; (below) RYC. yellow light are:

$$
\begin{gathered}
P B_{2}=P B_{0} \times e^{-2 \alpha_{B 2} h} \\
P Y_{2}=\frac{1}{2} \frac{\beta_{2} \times P B_{0}}{\alpha_{B 2}-\alpha_{Y 2}}\left(e^{-2 \alpha_{Y 2} h}-e^{-2 \alpha_{B 2} h}\right)
\end{gathered}
$$

In the above expressions, $\mathrm{h}$ indicates each phosphor film thickness; the subscripts 1 and 2 demonstrate the single-layer and dual-layer remote phosphor models, respectively, $\beta$ shows the conversion coefficient for blue light that converts to yellow light, while $\gamma$ expresses the yellow-light reflection coefficient. $\mathrm{PB}_{0}$ is the light intensity from the LED chip, which defines the intensities of blue light (PB) and yellow light (PY). $\alpha_{B}$ and $\alpha_{Y}$ are parameters describing the fractions of the energy loss of the blue light and the yellow light during their propagation in the phosphor layer.

The illuminating efficacy of the WLEDs employing two-layered phosphor packaging structure is much higher than that of the package with a single-layer structure:

$$
\frac{\left(P B_{2}+P Y_{2}\right)-\left(P B_{1}+P Y_{1}\right)}{P B_{1}+P Y_{1}}>0
$$

The scattering analysis of $\mathrm{Sr}_{\mathrm{w}} \mathrm{F}_{\mathrm{x}} \mathrm{B}_{\mathrm{y}} \mathrm{O}_{\mathrm{z}}: \mathrm{Eu}^{2+}, \mathrm{Sm}^{2+}$ particles was carried out based on the Mie theory. Additionally, the Mie theory was applied to calculate the scattering cross-section $\mathrm{C}_{\mathrm{sca}}$ for spherical particles. Besides that, the Lambert-law was used to reckon the power of transmitted light:

$$
I=I_{0} \exp \left(-\mu_{\text {ext }} L\right)
$$

where $\mathrm{I}_{0}$ represents the incident light power, and $\mathrm{L}$ is the thickness of the phosphor film (mm). The extinction coefficient $\mu_{\text {ext }}$ is defined as: $\mu_{\text {ext }}=$ $\mathrm{N}_{\mathrm{r}} \cdot \mathrm{C}_{\text {ext }}$, where $\mathrm{N}_{\mathrm{r}}\left(\mathrm{mm}^{-3}\right)$ and $\mathrm{C}_{\mathrm{ext}}\left(\mathrm{mm}^{2}\right)$ are the phosphor particles density distribution and extinction cross-section, respectively. According to equation 5, the illumination efficiency of WLEDs packaged with double-layer remote phosphor is greater than that of a single-layer phosphor. Furthermore, the study has successfully demonstrated the effectiveness of dual-layer remote phosphor configuration in terms of luminous flux. Fig. 6 shows that 
the emitted luminous flux increases sharply when $\mathrm{SrBaSiO}_{4}: \mathrm{Eu}^{2+}$ concentration rises from 2 wt. $\%$ to 20 wt.\%. However, the concentration of the red phosphor layer $\mathrm{Sr}_{\mathrm{w}} \mathrm{F}_{\mathrm{x}} \mathrm{B}_{\mathrm{y}} \mathrm{O}_{\mathrm{z}}: \mathrm{Eu}^{2+}, \mathrm{Sm}^{2+}$ greatly affects the luminous output of the two-layered remote phosphor. Obviously, based on the LambertBeer law, the reduction coefficient $\mu_{\text {ext }}$ is directly proportional to the $\mathrm{Sr}_{\mathrm{w}} \mathrm{F}_{\mathrm{x}} \mathrm{B}_{\mathrm{y}} \mathrm{O}_{\mathrm{z}}$ : $\mathrm{Eu}^{2+}, \mathrm{Sm}^{2+}$ content but inversely proportional to the light energy. Therefore, the luminous flux can be reduced if $\mathrm{Sr}_{\mathrm{w}} \mathrm{F}_{\mathrm{x}} \mathrm{B}_{\mathrm{y}} \mathrm{O}_{\mathrm{z}}: \mathrm{Eu}^{2+}, \mathrm{Sm}^{2+}$ concentration increases while maintaining the thickness of both WLEDs' phosphor layers. The reduction at two different CCTs is shown in Fig. 6. Accordingly, the luminous flux drops notably when the concentration of $\mathrm{Sr}_{\mathrm{w}} \mathrm{F}_{\mathrm{x}} \mathrm{B}_{\mathrm{y}} \mathrm{O}_{\mathrm{z}}: \mathrm{Eu}^{2+}, \mathrm{Sm}^{2+}$ achieves 26 wt.\%. However, this decrease does not cause any serious effect due to the advantages of the red phosphor layer $\mathrm{Sr}_{\mathrm{w}} \mathrm{F}_{\mathrm{x}} \mathrm{B}_{\mathrm{y}} \mathrm{O}_{\mathrm{z}}$ : $\mathrm{Eu}^{2+}, \mathrm{Sm}^{2+}$ including improving of CRI and CQS and the fact that double-layer remote phosphor package probably yields higher illuminating efficiency than the single-layer one (without red phosphor layer). The main point is how to select a suitable $\mathrm{Sr}_{\mathrm{w}} \mathrm{F}_{\mathrm{x}} \mathrm{B}_{\mathrm{y}} \mathrm{O}_{\mathrm{z}}: \mathrm{Eu}^{2+}{ }^{2+} \mathrm{Sm}^{2+}$ concentration to meet the demand of customer when producing these WLEDs in batch.

\section{Conclusions}

In conclusion, the effect of green phosphor $\mathrm{SrBaSiO}_{4}: \mathrm{Eu}^{2+}$ and red phosphor $\mathrm{Sr}_{\mathrm{w}} \mathrm{F}_{\mathrm{x}} \mathrm{B}_{\mathrm{y}} \mathrm{O}_{\mathrm{z}}: \mathrm{Eu}^{2+}, \mathrm{Sm}^{2+}$ on the CRI, CQS, and luminescence of dual-layer phosphor structure has been presented in this paper. As a result of employing the Mie-scattering theory and the Lambert-Beer law in the investigation, the red phosphor $\mathrm{Sr}_{\mathrm{w}} \mathrm{F}_{\mathrm{x}} \mathrm{B}_{\mathrm{y}} \mathrm{O}_{\mathrm{z}}: \mathrm{Eu}^{2+}, \mathrm{Sm}^{2+}$ has been chosen for improving WLEDs color quality. Meanwhile, the green phosphor $\mathrm{SrBaSiO}_{4}: \mathrm{Eu}^{2+}$ turned out to be the right choice to improve the luminous flux of WLEDs having low CCT $(6600 \mathrm{~K})$ and even high CCT (above $7700 \mathrm{~K}$ ). Thus, the objective which was the improvement of white light quality - a challenging issue for remotephosphor structure, has been reached in this paper although there is still a slight disadvantage as the color quality or luminous flux of WLEDs decreases remarkably when the $\mathrm{SrBaSiO}_{4}: \mathrm{Eu}^{2+}$ or $\mathrm{Sr}_{\mathrm{w}} \mathrm{F}_{\mathrm{x}} \mathrm{B}_{\mathrm{y}} \mathrm{O}_{\mathrm{z}}: \mathrm{Eu}^{2+}, \mathrm{Sm}^{2+}$ concentration increases extremely. Hence, the selection of an appropriate concentration for these two phosphors is essential in producing WLEDs with higher quality. The general knowledge and necessary information related to this process have been provided in this article.

\section{Acknowledgements}

This research is funded by Foundation for Science and Technology Development of Ton Duc Thang University (FOSTECT), website: http://fostect.tdt.edu.vn, under Grant FOSTECT.2017.BR.06.

\section{References}

[1] BAJAJ N.S., Koparkar K.A., NAgPuRe P.A. OMANWAR S.K., J. Opt., 46 (2017), 91.

[2] Shen C., Chu J., Qian F., Zou X., Zhong C., LI K., Jin. S., J. Mod. Opt., 59 (2012), 1199.

[3] Lin H.Y., Wang S.W., Lin C.C., Tu Z.Y., LeE P.T. Chen H.M., Kuo H.C., Opt. Exp., 24 (2016), 19032.

[4] Kim E., Unithrattil S., Sohn I.S., Kim S.J., Chung W.J., IM W.B., Opt. Mater. Exp., 6 (2016), 804.

[5] LeE Y.K., Kim Y.H., Heo J., IM W.B., Chung W.J., Opt. Lett., 39 (2014), 4084.

[6] OH J.H., Kang H., Ko M., Do Y.R., Opt. Exp., 23 (2015), A791.

[7] Xu J., Ueda J., Tanabe S., Opt. Mater. Exp., 5 (2015), 963

[8] Sijbom H.F., Verstraete R., Joos J.J., Poelman D., SMet P.F., Opt. Mater. Exp., 7 (2017), 3332.

[9] Matsushima K., Sonobe N., Appl. Opt., 57 (2018), A150.

[10] Cantore M., Pfaff N., Farrell R.M.., Speck J.S., NaKamura S., DenbaARs S.P., Opt. Exp., 24 (2016), A215.

[11] Peng Y., Wang S., Li R., Li H., Cheng H., Chen M., LIU S., Appl. Opt., 55 (2016), 4933.

[12] Kawano Y., Kim S.W., Ishigaki T., Uematsu K., Toda K., TAKABA H., SATO M., Opt. Mater. Exp., 4 (2014), 1770.

[13] Peng Y., Mou Y., Guo X., Xu X., Li H., Chen M., LUO X., Opt. Mater. Exp., 8 (2018), 605.

[14] Sun S., Wu L., Yi H., Wu L., Ji J., Zhang C., ZHANG Y., Kong Y., XU J., Opt. Mater. Exp., 6 (2016), 1172.

[15] Lee C., Shen C., Cozzan C., Farrell R.M., Speck J.S., NaKamura S., OOI B.S., Denbaars S.P., Opt. Exp., 25 (2017), 17480.

[16] Zhang F., Xu H., Feng H., Appl. Opt., 56 (2017), 8186.

[17] Ke H.L., Jing L., Hao J., GaO Q., Wang Y., Wang X.X., Sun Q., Xu Z.J., Appl. Opt., 55 (2016), 5909.

[18] Guo Z., Lu H., Shin T., Lin Y., LU Y., Chen Z., $J$ Disp. Technol., 12 (2016), 1393. 
[19] Ying S.P., Fu H.K., Hsieh H.H., Hsieh K. Y., Appl. Opt., 56 (2017), 4045.

[20] Chen L.Y., Chang J.K., Cheng W.C., Huang J.C., Huang Y.C., Cheng W.H., Opt. Exp., 23 (2015), A1024.

[21] LiU Y., Zou J., Yang B., Li W., Shi M., Han Y., WANG Z., Li M., JiAng N., Mater. Technol., 33 (2017), 22.
[22] Yen W.M., Weber M.J., Inorganic Phosphors: Compositions, Preparation and Optical Properties, CRC Press, LLC, 2000 N.W. Corporate Blvd., Boca Raton Florida 33431, 2004.

Received 2018-12-21

Accepted 2019-04-23 